\title{
LA DIPLOMACIA CULTURAL EN LA POLÍTICA EXTERIOR BRASILEÑA. UN ANÁLISIS COMPARADO DE DOS MOMENTOS DE TRANSICIÓN MATRICIAL
}

\author{
CULTURAL DIPLOMACY IN BRAZILIAN FOREIGN POLICY. \\ A COMPARATIVE ANALYSIS OF TWO MOMENTS OF \\ MATRIX TRANSITION
}

\begin{abstract}
LA DIPLOMATIE CULTURELLE DANS LA POLITIQUE ÉTRANGÈRE DU BRÉSIL. UNE ANALYSE COMPARATIVE DE DEUX MOMENTS DE TRANSITION FONDAMENTAUX
\end{abstract}

\author{
Camila SaUte Torresini \\ Universidad Federal de Río Grande del Sur \\ camila.storresini@gmail.com \\ Caroline Chagas de Assis \\ Universidad Federal de Río Grande del Sur \\ carolinechagasdeassis@gmail.com \\ KARINA RUIZ \\ Universidad Federal de Río Grande del Sur \\ kpbruiz@gmail.com
}

Resumen: Este artículo problematiza el papel del Estado brasileño en la elaboración de la diplomacia cultural del país, al comparar los momentos en que se identifica una participación más asertiva de este actor en la formulación de sus directrices, a partir de la redemocratización de Brasil. Para ello, la hipótesis propuesta consiste en que los gobiernos de José Sarney (1985-1990) y Lula da Silva (2003-2010) constituyen dos momentos de transición matricial en la política exterior brasileña, en los que el Estado asumió una función más vigorosa en la articulación de la diplomacia cultural. Con base en la revisión bibliográfica de registros oficiales y de obras especializadas, comienza este análisis con una dilucidación teórica sobre lo que se concibe como diplomacia cultural en la política exterior brasileña y continúa con la comparación entre ambos períodos de transición matricial apuntados a la luz de la actuación del Estado en la conformación de la diplomacia cultural del país.

Palabras clave: diplomacia cultural, política exterior brasileña. 
Abstract: This article discusses the role of the Brazilian state in the development of the country's cultural diplomacy, comparing moments in which a more assertive participation of the state is identified in the formulation of its guidelines, following the return of democracy to Brazil. The hypothesis proposed is that the governments of José Sarney (1985-1990) and Lula da Silva (2003-2010) constitute two moments of matrix transition in Brazilian foreign policy, in which the state took on a more dynamic role in the articulation of cultural diplomacy. Based on the bibliographic review of official records and specialized works, this analysis begins with a theoretical explanation of what is conceived as cultural diplomacy in Brazilian foreign policy, and continues with a comparison between the two periods of matrix transition, in the light of the state's actions in shaping the country's cultural diplomacy.

Keywords: cultural diplomacy, Brazilian foreign policy.

Traducción de Gonzalo Celorio Morayta

Résumé: L'article examine le rôle de l'État brésilien dans la formulation de la diplomatie culturelle du pays, surtout aux moments où la volonté d'établir les principes de celle-ci a été la plus forte, après le retour de la démocratie au Brésil. Nous proposons une hypothèse, que les gouvernements de José Sarney (1985-1990) et Lula da Silva (2003-2010) ont été deux étapes essentielles dans la transition de la politique étrangère, où l'État a déployé le plus de vigueur dans le but d'articuler la diplomatie culturelle. En nous appuyant sur des documents officiels et des ouvrages spécialisés, nous nous occupons d'abord de la manière dont la politique étrangère brésilienne a imaginé la diplomatie culturelle, ensuite nous comparons les deux périodes de transition au cours desquelles l'État l'a dotée d'une forme.

Mots clefs: Diplomatie culturelle, politique étrangère brésilienne.

Traducción de BERnardo Mabire

Fecha de recepción: octubre de 2016 Fecha de aceptación: agosto de 2017 
C ubestimar la dimensión cultural va en detrimento de áreas como la política, la economía y la seguridad, pero es, aún en la actualidad, una característica común en los análisis de la Política Exterior de Brasil (РEB).* Frente a este hecho, el presente trabajo cuestiona la función conferida al Estado brasileño, a partir de la redemocratización interna, en la conformación de la política exterior del país en el aspecto cultural, con el propósito de comparar los momentos en que se identifica una participación más asertiva del Estado en la formulación de sus directrices.

La redemocratización del país constituye el marco temporal de este análisis luego de examinar, como hace Eli Diniz, ${ }^{1}$ que la democracia conlleva una nueva perspectiva para la formación en Brasil de un pensamiento sobre desarrollo. Considerando la nueva era de globalización iniciada en la década de los años ochenta, Diniz señala que el fenómeno ha ido exigiendo, sobre todo a principios del siglo XXI, un diálogo constante entre la sociedad civil y el Estado para alcanzar un verdadero desarrollo. Como el papel de esta última institución radica en promover posibilidades de cambio en las políticas públicas, se entiende que tal funcionamiento acabe por extenderse a todos los ámbitos de la política del país, incluida la exterior, y, en consecuencia, la DC. Se parte así de la idea de transición matricial de Ricardo Sennes, según la cual la PEB se caracteriza por hacer cambios matriciales que surgen de las coyunturas interna y externa, y se deduce que la DC, como consecuencia de formar parte de la política exterior, repite el procedimiento. En ese sentido, la hipótesis por comprobarse es que, desde la consolidación de la redemocratización interna, los momentos de transición matricial marcados por los gobiernos de José Sarney (19851990) y Lula da Silva (2003-2010) se llevaron a cabo cuando

* Agradecimento especial ao Professor Dr. André da Silva Reis pelas contribuições da disciplina de Política Externa Brasileira III.

1 "Desenvolvimento e Estado desenvolvimentista: tensões e desafios da construção de um novo modelo para o Brasil do século xxı", Revista de Sociologia e Política, vol. 21, num. 47, 2013, pp. 9-20. 
el Estado desempeñó un papel de mayor relevancia en la conformación de las directrices de la DC de Brasil.

A partir de una revisión bibliográfica exhaustiva de discursos y registros oficiales, así como de obras de autores especializados, este análisis se desarrolla desde un enfoque cualitativo y deductivo. Además de la presente "Introducción", el artículo se divide en cuatro apartados en que se presenta la estructura del análisis por realizarse. El primero intenta elucidar la importancia de la DC en la política exterior formulada por el Estado brasileño, analizándola en los ámbitos, primero, de las Relaciones Internacionales y, luego, de la PEB. De esta manera, se enuncian las bases para efectuar la comparación propuesta como objetivo último de la investigación.

En los capítulos segundo y tercero se analiza la participación del Estado en la formulación de la DC durante los mandatos de José Sarney y Lula da Silva. El estudio de cada uno de los gobiernos se desarrolla según las siguientes directrices: 1) elucidación de los aspectos que llevaron a utilizar la transición matricial en cuestión; 2) el contexto histórico del periodo, y 3) principales políticas culturales del periodo. Por último, las consideraciones finales del estudio retoman los aspectos del análisis para esbozar un panorama de las semejanzas y diferencias entre los dos momentos de la transición matricial de la PEB a partir de la función del Estado como promotor de la DC del país. Así se justifica el análisis, sobre todo al llevar a la mesa de debate académico una DC idealizada y practicada por el Estado brasileño, tema todavía poco explorado en los estudios sobre la política exterior del país.

LA GULTURA GOMO FORMA DE PODER DE LOS ESTADOS:

LA IMPORTANCIA DE LA DIPLOMACIA CULTURAL

EN LA POLÍTICA EXTERIOR BRASILEÑA

Para entender la importancia que la DC tiene para la PEB, en este apartado se establecen dos propósitos específicos en el ámbito de la formulación de la política exterior del Estado 
brasileño: comprender la idea de diplomacia cultural en el marco de las Relaciones Internacionales y, después, en el de la Рев. Primero, se discute el espacio conferido a la cultura como dimensión de poder en el ámbito de las Relaciones Internacionales a partir del análisis teórico de conceptos como cultura, podery DC. Después, se reúne el pensamiento de autores de diversas corrientes de las ciencias sociales más allá de las Relaciones Internacionales, con el fin de fundamentar lo que en este artículo se entiende por diplomacia cultural. Esta idea, por último, se estudia como recurso de la política exterior del país y se explica el supuesto teórico de los cambios matriciales de la PEB, fundamento del análisis comparado propuesto en este artículo.

En oposición a la tendencia de relegar a segundo plano el aspecto cultural, importantes estudiosos del tema coinciden en que la cultura es una manifestación complementaria relacionada con los demás elementos que definen el poder de los Estados en el sistema internacional (sI). Es el caso de Stuart Hall, quien entiende que la cultura, aunque participa en el juego del poder, no es un aspecto de poder concreto, sino simbólico y discursivo, pues "todas las conductas y acciones de la sociedad son reguladas normativamente por un significado cultural". ${ }^{2}$ Antonio Gramsci, sin embargo, ya había concebido la cultura como uno de los medios de las clases dominantes para crear un consentimiento espontáneo en las clases dominadas, lo que promueve una combinación de coerción y consenso en cuanto a la cultura de valores hegemónicos. ${ }^{3}$ En tal sentido, nuestro análisis considera impres-

2 "The centrality of culture: notes on the cultural revolutions of our time", en Kenneth Thompson (ed.), Media and cultural regulation, Thousand Oaks, Sage Publications, 1997, p. 233, en www.henryagiroux.com/ links/centrality of culture.pdf, consultado el 28.V.2016. La traducción de todas las citas, tanto en el cuerpo del trabajo, como en las notas a pie de página, corresponde a los autores.

${ }^{3}$ H. C. de Castro, "Cultura política, democracia e hegemonía", en Gramsci e o Brasil, 2000, en www.acessa.com/gramsci/?page=visualizar\&id= 102, consultado el 6.IV. 2016. 
cindible el pensamiento de Joseph Nye para entender la relación entre cultura y poder en el ámbito de las Relaciones Internacionales, toda vez que establece la diferenciación entre el tradicional hard power, que consistiría en recursos materiales de poder, mensurables fácilmente por ser más concretos, y su concepción de soft power, que serían las formas de poder más sutiles, pero igualmente determinantes de las capacidades de los Estados. Desde esa visión, la cultura sería una forma de soft power de los Estados, por su capacidad de alterar acciones e intereses de otros actores sin operar activamente, sino mediante la seducción y la atracción que representan sus fines y preferencias. ${ }^{4}$ Es así como Nye propone sustituir la idea de coerción por la de cooptación para el análisis de procesos ideológicos y hegemónicos. ${ }^{5}$ Robert Cox entrevé en la creación de un sistema de normas e instituciones por un poder hegemónico, una forma de persuasión y adaptación a sus intereses, incluso menos costosa, y coincide con Nye en que el soft power es capaz de mantener el modo de producción vigente favorable a los poderes hegemónicos en el si. ${ }^{6}$

Aunque se reconozca que hay diferencias entre los tipos de poder de los Estados, se entiende que la designación soft y hard puede conducir, aun sin proponérselo, a la idea de que el "poder blando" es relativamente menos importante en la esfera de poder de los Estados, por lo que decidimos no adoptarlo en este análisis, pues nos interesa realzar la dimensión cultural como elemento de idéntica importancia a los

${ }^{4}$ Soft power: The means to success in world politics, Cambridge, Public Affairs, 2004.

${ }^{5}$ Según Nye, es difícil percibir la verdadera relación de causa-efecto entre el poder militar y el económico y la hegemonía; su noción de hegemonía, por cierto, diverge de la neomarxista, tanto por el aspecto temporal cuanto por el énfasis puesto en las empresas de los Estados, de ahí el surgimiento del nuevo concepto. Cf. J. S. Nye, "The changing nature of world power”, Political Science Quarterly, vol. 105, núm. 2, 1990, pp. 177-192, en http://members.shaw.ca/compilerpress1/Anno\%20Nye.htm, consultado el 18.VII.2016.

${ }^{6}$ Production, power and world order: Social forces in the making of history, Nueva York, Columbia University Press, 1987. 
demás recursos de poder en el análisis en Relaciones Internacionales. Al final, como consigna Hall, "la cultura no puede estudiarse más como una variable de menor importancia, secundaria y dependiente en relación con lo que lleva a funcionar al mundo moderno, sino que debe observarse como algo primario y constitutivo, determinando su forma y su carácter". 7 De cualquier forma, en la medida en que todos los pensamientos expuestos convergen en la importancia del factor cultural como forma de poder en las Relaciones Internacionales, se entiende que tal aspecto se convierte en factor de relevancia vital en la formulación de la estrategia en la política exterior de los países. De ahí la importancia de comprender el significado de la noción de "diplomacia cultural" que se ha adoptado en este análisis. He aquí la definición del propio Ministerio de Relaciones Exteriores de Brasil (MRE):

La diplomacia cultural es un instrumento importante de aproximación entre los pueblos que contribuye a abrir mercados para la industria cultural y para el establecimiento de vínculos culturales y lingüísticos. Y, también, herramienta para estimular los diálogos político y económico, pues fomenta el entendimiento mutuo y crea confianza, interés y respeto entre las naciones $[\ldots]$. Si por un lado resalta la singularidad de nuestra cultura, por el otro revela las afinidades que unen a otros pueblos -particularmente significativas, ya que nuestro país acogió flujos migratorios de los más diversos orígenes. ${ }^{8}$

Emil Constantinescu, presidente de la Academia de Diplomacia Cultural del Instituto de Diplomacia Cultural, tiene una visión cercana a la de la MRE al considerar la DC como una serie de acciones apoyadas en el intercambio de los más diversos aspectos de cultura e identidad de un país para fortalecer sus relaciones con otros países y promover intereses naciona-

${ }^{7}$ Art. cit., p. 215.

${ }^{8}$ MRE, "Diplomacia cultural", 2016, en www.itamaraty.gov.br/pt-BR/ diplomacia-cultural, consultado el 13.V.2016. 
les. ${ }^{9}$ En ese mismo sentido va también Edgard Telles Ribeiro, quien entiende la DC como el medio apropiado tanto para afianzar la identidad nacional dentro y fuera del país, cuanto para consolidarse internamente, y por ello propone dos frentes de actuación. En el ámbito internacional, la DC impulsa la conciliación entre principios, valores e ideologías para fomentar la aproximación entre los pueblos, atenuar la desconfianza mutua y promover la cooperación internacional. En el nacional, la DC apela a la intermediación entre las demandas internas y externas con el afán de concretar los objetivos nacionales más allá del área cultural, ya sean políticos, económicos o comerciales. ${ }^{10}$ En consonancia con las ideas aquí presentadas, este artículo concibe la DC como recurso de la política exterior para promover un país, mediante su cultura, en el resto del mundo. La valoración de la cultura nacional en la política exterior es importante por su capacidad de favorecer el posicionamiento del país en el sistema internacional, prevenir el dominio epistemológico e influir en la consolidación de su identidad y su desarrollo. Entonces, al buscar conciliar cuestiones internas y externas de un país, se entiende que la DC fomenta la búsqueda del interés nacional.

Conviene mencionar, sin embargo, la diferenciación del análisis en lo relativo a la articulación de este instrumento en el ámbito de la política exterior. Para autores como Constantinescu, diversos participantes pueden practicar la DC: el sector público, el privado o la sociedad civil. ${ }^{11}$ En la medida en que nuestro trabajo se propone analizar la diplomacia cultural como recurso de política exterior practicada por el Estado brasileño, es necesario diferenciarla de lo que algunos

${ }^{9}$ K. Chakraborty (ed.), Cultural Diplomacy Dictionary, Berlín, Institute for Cultural Diplomacy, 2013, p. 30, en www.cd-n.org/content/pdf/Cultural_Diplomacy_Dictionary.pdf, consultado el 11.VI.2017.

${ }^{10}$ E. T. Ribeiro, Diplomacia cultural: seu papel na política externa brasileira, Brasilia, Fundação Alexandre de Gusmão (FUNAG), 2011, en http:// funag.gov.br/loja/download/824-Diplomacia_Cultural_-_Seu_papel_ na_PolItica_Externa_Brasileira_2011.pdf, consultado el 18.VII.2016.

${ }^{11}$ Chakraborty, op. cit., p. 31. 
autores llaman relaciones culturales internacionales. A partir de lo que señala John Mitchell, la diferencia principal reside en el hecho de que estas últimas son llevadas a cabo por actores de la sociedad civil, mientras que la diplomacia cultural se basa en la coordinación de las acciones por parte del Estado. En esa misma línea, Ribeiro defiende que las relaciones culturales pretenden desarrollar instituciones de aprovechamiento mutuo entre los pueblos, en oposición a la DC, que utiliza la relación cultural específicamente para concretar los objetivos del país. ${ }^{12}$

Por lo mismo, vale señalar aquí que la diplomacia cultural no puede confundirse con la diplomacia pública, porque ésta actúa para comunicar las políticas internacionales adoptadas por el Estado a sus ciudadanos y al resto del mundo y para promover la imagen del país en el exterior mediante la apertura de la política exterior a la opinión pública y a grupos e intereses privados, como un esfuerzo de democratización y transparencia de las políticas públicas nacionales. Este análisis entiende así que la diplomacia cultural, como parte de la política exterior de un país, está supeditada a su dimensión pública y al influjo del comportamiento de la sociedad civil sobre la formación y ejecución de sus iniciativas. ${ }^{13}$ Cabe señalar también que el designio de la DC de elevar la imagen del país en el exterior no puede confundirse con la idea de la propaganda política, herramienta de comunicación partidaria utilizada para divulgar idearios político-partidistas y reclutar votos. ${ }^{14}$ Inducir a que la legislación en Brasil establezca la división de este género entre lo electoral, los partidos y la partidaria deja en claro su intervención en la política interna, con lo que se aparta sustancialmente de la idea de divulgación de la imagen del país en el exterior.

La mayoría de los especialistas en el tema considera que la diplomacia cultural tuvo su origen en Europa, cuando Fran-

12 Ribeiro, op. cit.

13 MRE, "Diplomacia pública", 2017, en www.itamaraty.gov.br/pt-BR/ diplomacia-publica, consultado el 11.VI.2017.

${ }^{14}$ Chakraborty, op. cit., p. 78. 
cia incorporó su cultura por primera vez al universo de la política exterior en el siglo xIx. En la etapa de entreguerras del siglo siguiente, correspondió a Gran Bretaña, España, Estados Unidos (EUA) ${ }^{15}$ Italia $^{16}$ y México. ${ }^{17}$ Es importante señalar la actuación del Comité Internacional para la Cooperación Intelectual de las Naciones Unidas (CICI) en el periodo que comprende los años de 1922 a 1945, toda vez que se hicieron las iniciativas multilaterales de los Estados para coordinar sus políticas exteriores en lo que toca a la cultura; en 1946, por cierto, esta institución se convertiría en la actual Organización de las Naciones Unidas para la Educación, la Ciencia y la Cultura (Unesco). ${ }^{18}$ Pero en el periodo antes mencionado, concretamente en 1929, se consolidó además un departamento especializado en la cooperación cultural en el ámbito de la Unión Panamericana, institución que dio origen a la Organización de los Estados Americanos (oEA) en 1948, y cuya actuación fue cada vez más significativa en el área cultural. ${ }^{19}$ Así surgía también la DC como instrumento de cooperación internacional que buscaba el diálogo entre los actores del si. Después de la Segunda Guerra, Canadá incorporó la diplomacia cultural a su política exterior, seguida de la República Federal de Alemania y de Japón en los años sesenta. ${ }^{20}$

A partir de la consumación de la Guerra Fría y del incremento de la globalización, la interdependencia en el si comenzó a darse con más rapidez e intensidad, y no solamente

15 Cf. C. A. Thomson, "The Emerging Program of Cultural Relations", ALA Bulletin, vol. 38, núm. 2, 1943-1944, pp. 75-81, y R. T. Arndt, The First Resort of Kings: American Cultural Diplomacy in the Twentieth Century, Washington, D. C., Potomac Books, 2005.

${ }^{16}$ Cf. Ribeiro, op. cit.

${ }^{17}$ Cf. P. Yankelevich, Miradas australes: propagandas, cabildeo y proyección de la Revolución Mexicana en el Río de la Plata, 1910-1930, México, Instituto Nacional de Estudios Históricos de la Revolución Mexicana, 1997, y A. Córdova, La revolución y el Estado en México, México, Era, 1989.

${ }^{18}$ UNESCO, The Organization's history, 2017, en http:/ /www.unesco.org/ new/en/unesco/about-us/who-we-are/history/.

19 OEA, Quem somos, 2017, y OEA y SEDI, Diálogo político, 2017.

${ }^{20}$ Ribeiro, op. cit. 
en términos económicos y políticos. Rogelio Suppo, con base en la idea de Marcel Merle, sostiene que la internacionalización de los fundamentos de cultura e identidad de los Estados reflejaba así la necesidad de mecanismos que abarcaran un espacio internacional en que las relaciones ya no fueran meramente interestatales o transnacionales, sino interculturales. ${ }^{21}$ Como Ribeiro consigna, influido por el pensamiento de Mitchell, en un ambiente global en que la creciente interdependencia se transporta también al campo cultural, las iniciativas tienen gran oportunidad de influir en las demás áreas de la política exterior. Al final, el área económica involucró a la DC en las cadenas globales de valor, de tal manera que la industria cultural repercutió notablemente en el posicionamiento de los países en el si. Para Mitchell, los países desarrollados se anticiparon en esta percepción y, por lo mismo, en la actualidad se encuentran en una posición privilegiada en relación con los países en vías de desarrollo, que se acostumbraron a invertir sus escasos recursos en otras áreas que consideraron prioritarias. ${ }^{22}$

Brasil logró ser uno de los precursores en el uso de tal instrumento de política exterior en América Latina, según señalan Juliette Dumomnt y Anaís Fléchet. La DC se consolidó en la PEB a pesar de que la cultura brasileña no descolló en el plano internacional hasta finales del siglo xix y de que, después de la Primera Guerra Mundial, el país había sido simple receptor de las políticas culturales francesas y estadounidenses, ${ }^{23}$ como sucedió también con otros países

${ }^{21}$ Cf. M. L. Lessa y R. Suppo (orgs.), A quarta dimensão das Relações Internacionais: a dimensão cultural, Río de Janeiro, Contra Capa, 2012, pp. 169-192.

${ }^{22}$ Ribeiro, op. cit.

${ }^{23}$ Coincidentemente, o no, Wallerstein (World-system analysis: an introduction, Londres, Duke University Press, 2004) señala la preponderancia de apenas dos "geoculturas" en el sistema internacional hasta el día de hoy: Francia y Estados Unidos sobresalen, respectivamente en los siglos xx y xxI, como los únicos Estados que alcanzaron un dominio geopolítico utilizando la cultura como recurso preponderante de política exterior. Nye 
desarrollados. Para las autoras, este instrumento legitima los intereses estratégicos del país en el mundo: "a partir de los años 1920, el Itamaratí defendió una política cultural pragmática, cuyos contenidos y estructuras sufrieron importantes modificaciones conforme el periodo, el régimen político, la composición del cuerpo diplomático y las diferentes concepciones de su identidad nacional". ${ }^{24} \mathrm{Al}$ final, como percibe Leticia Pinheiro, ${ }^{25}$ la política exterior a lo largo de la historia de Brasil tendía tanto a aceptar la condición de inferioridad del país en el si, como a superar la situación de subdesarrollo, característica que se reflejó en la DC elaborada por el Estado:

¿Pudiera ser que a pesar de la importancia de la cultura para la sociedad brasileña, todavía no contenía la importancia que ocupa en otras sociedades? $\mathrm{O}$ ¿es la cultura uno de los pilares de la política de Estado del país? Por otro lado, debe considerarse, como cualquier país periférico, [que] Brasil tiene otras prioridades que no sólo canalizan recursos y esfuerzos que, todavía, oscurecen la visión e importancia de la cultura. Estos factores internos repercuten, naturalmente, en la política exterior brasileña y, en consecuencia, en su diplomacia cultural que se impone con menos vigor en el escenario político internacional. ${ }^{26}$

("Limits of american power", Political Science Quarterly, vol. 117, núm. 4, 2002, pp. 545-559, en http:/ / www-bcf.usc.edu/ stables / nye.pdf, consultado el 18.VII.2016) considera que estos países representan la vanguardia en la percepción de la cultura como uno de los elementos centrales en la política exterior, aun antes de pensar en la diplomacia cultural como tal.

${ }^{24}$ J. Dumont y A. Fléchet, "Pelo que é nosso!: a diplomacia cultural brasileira no século xx", Revista Brasileira de História, vol. 34, num. 6, 2014, p. 203, en www.scielo.br/pdf/rbh/v34n67/a10v34n67.pdf, consultado el 10.V.2016.

${ }^{25}$ L. Pinheiro, "Traídos pelo desejo: um ensaio sobre a teoria e a prática da política externa brasileira contemporânea”, Contexto Internacional, vol. 22, núm. 2, 2000, pp. 305-335.

26 M. Lessa, "Bens e Serviços Culturais: o lugar do Brasil na Cena Internacional (2001-2006)", en $32^{\circ}$ Encontro Anual da Anpocs. GT10 Cultura, Economia e Política, p. 3, en http://www.anpocs.com/index.php/pa- 
Tal característica dual de la PEB refleja su histórica oscilación entre la preponderancia ora del mercado, ora del Estado en su articulación, lo que se manifiesta en la DC idealizada y practicada por el Estado, vista la cultura como uno de los campos adecuados para la proyección internacional del país y, por lo tanto, sujeta a acompañar los lineamientos más generales de la política exterior. Por ello, este análisis asocia las tendencias de la DC a los cambios matriciales de la política exterior del país. Cabe señalar, antes de explicar esta idea, que con base en la inexorable relación entre lo interno y lo externo en el ámbito político y en la noción de que la democracia conlleva una nueva perspectiva para la formación de un pensamiento sobre desarrollo en el país, que afecta, en consecuencia, su política exterior, se justifica la redemocratización de Brasil a partir de 1985, marco temporal de este trabajo. ${ }^{27}$ Dicho esto, se parte de la idea de Ricardo Sennes concerniente a las matrices de política exterior en Brasil desde los años ochenta. Según este autor, el concepto

refiere a los contornos más generales de la política exterior de un país y busca determinar la forma en que concibe la dinámica del sistema internacional [...] [que tiende a] sufrir procesos de cambios en espacios de tiempo más extensos que el lapso de duración de los gobiernos, principalmente en los regímenes presidencialistas.

Sennes sugiere que, en ese contexto, tal estructura pasa por periodos de transición, en que se da cierta convivencia entre dos modelos distintos de política exterior, hasta que el sistema se adapta a la nueva "matriz". Ambos modelos convergen de manera general con los momentos de la PEB propuestos por los "paradigmas” de Amado Cervo, así como con las "estrategias" de Gabriel Cepaluni y Tullo Vigevani. Mientras que

pers-32-encontro/gt-27/gt10-21/2383-monicalessa-bens/file, consultado el 3.V.2016.

${ }^{27}$ Diniz, art. cit. 
Sennes destaca el paso de la llamada matriz desarrollista a la matriz emergente durante el gobierno de Sarney (1985-1990), los demás autores proponen un último movimiento transitorio motivado por la entonación desigual de la política exterior identificada desde el gobierno de Lula (2003-2010), considerado en este artículo una nueva transición matricial.

Los dos gobiernos de Sarney y Lula son característicos de las dos transiciones que culminaron en el inicio de posturas estatales significativas en la DC brasileña desde la consolidación del proceso de redemocratización del país. En el primer momento, sin importar que el Estado perdiera espacio como articulador de la PEB, en detrimento de un mercado que comenzaba a ganar fuerza, se intentó mantener la política desarrollista anterior, reflejada en la DC mediante la creación de instituciones de fomento a la cultura. Sin embargo, con el aumento de la utilización de leyes que incentivaban el mercado, se originó el retiro del poder de decisión y de planeación del Estado en la cultura, con que se perjudicó orientaciones incluso previstas en la ley y se fomentó un modelo de Estado inversor por encima de uno planificador.

Si bien esta tendencia predominaría en los mandatos siguientes, las discusiones que se sostuvieron durante los gobiernos de Lula levantaron un debate sobre las bases heredadas del primer periodo. Al final, y a pesar de haberse mantenido el predominio del mecanismo indirecto en el fomento a la cultura, el descontento con las políticas neoliberales provocó que el Estado se hiciera cargo de ellas en función de articulador, pero aliándose al mercado y a la sociedad civil en ese mismo sentido. A partir de entonces, se crearon nuevos mecanismos de incentivos y reformulación de instituciones que posibilitaron el desarrollo de la DC del país y hasta proyectos relacionados con la cooperación en América del Sur. Justificada así la propuesta de análisis comparado en este artículo, en las secciones siguientes se desarrollará el estudio de estos periodos. 


\section{Diplomacia CUltural EN LA POlítica EXTERIOR DE SARNEY}

Si bien se puede hablar de políticas culturales del Itamaratí desde 1920, a partir de 1930 se observó que había necesidad de actores colectivos, de intervenciones conjuntas y sistemáticas y de metas aunadas a las políticas culturales, para poder hablar de políticas culturales internas. ${ }^{28}$ En ese sentido, Silva ${ }^{29}$ indica que la institucionalización de las políticas culturales se llevó a cabo entre los años de 1930 y 1989, lo que llegó a su auge durante el gobierno de Sarney (1985-1999). Desde 1964, año en que se formó el primer frente civil electo por el Código Electoral, su gobierno consolidó el proceso de transición democrática, iniciado en el gobierno de Geisel (1974-1979), al promover reformas para evitar rupturas significativas. ${ }^{30}$ Con ello se iniciaba un periodo que Diniz percibe como de "fuerte inspiración por cambios en el estado de cosas en vigor [...] caracterizando una inflexión política que daría paso al cambio en la selección de políticas públicas". 31

La política exterior del gobierno de Sarney -y, en consecuencia, su diplomacia cultural- heredó las líneas gene-

28 A. A. C. Rubim, "Políticas culturais no Brasil: tristes tradições", $G a$ láxia. Revista do Programa de Pós-Graduação em Comunicação e Semiótica, núm. 13, 2007, en https://revistas.pucsp.br/index.php/galaxia/article/ view/1469, consultado el 4.VI.2017.

${ }^{29}$ R. M. D. da Silva, "As políticas culturais brasileiras na contemporaneidade: mudanças institucionais e modelos de agenciamento”, Sociedade e Estado, vol. 28, núm. 1, 2014, pp. 199-224, en www.scielo.br/scielo. php?script=sci_arttext\&pid=S0102-69922014000100011, consultado el 1.VI.2017.

30 Cf. C. Fonseca, "A Política Externa Brasileira da Democracia. O paradoxo da mudança na continuidade?”, Relações Internacionais, núm. 29, 2011, en www.scielo.mec.pt/scielo.php?script=sci_arttext\&pid=S1645-919 92011000100003, consultado el 4.VI.2017, y B. Fausto, História do Brasil, São Paulo, Editora da Universidade de São Paulo, 1995.

31 Art. cit., pp. 11-12. 
rales de lo que Sennes denomina matriz desarrollista. ${ }^{32}$ De esta forma, el inicio del gobierno se mantuvo próximo a los países del Tercer Mundo y atento a las relaciones regionales, ${ }^{33}$ mientras que hacía ajustes necesarios al periodo democrático. La década de los años ochenta estuvo marcada, sin embargo, por profundos cambios en la si. Como señala Sennes, el rompimiento de las reglas económicas establecidas en la posguerra y los cambios tecnológicos del periodo estuvieron acompañados por una ofensiva de los países desarrollados, por la distensión del final de la Guerra Fría y por la desarticulación del Tercer Mundo. En consecuencia, la matriz desarrollista dejaría de responder a las necesidades del país al final de la década de los años ochenta.

Las relaciones entre Brasil y Estados Unidos fueron determinantes para el desajuste matricial. La baja en la generación de superávits comerciales en un entorno en que se diluía la unidad tercermundista y se retraía la participación de estos países en el comercio internacional originó un mayor acercamiento con los países considerados desarrollados, especialmente con los Estados Unidos, país que, además, sumó la promoción de negociaciones cruzadas de temas financieros y comerciales, de modo que Brasil, con su capacidad de negociación debilitada, se veía cada vez más expuesto a las presiones de las reformas económicas.

De esa forma, la "limpieza de agenda" que buscaba rectificar posturas características del periodo dictatorial cedía es-

32 Después de considerar que durante la década de los años setenta Brasil entró en el Sistema Internacional como país recién industrializado, Sennes (op. cit.) señala tres líneas básicas de la matriz desarrollista: la identificación del país como potencia intermedia; una alineación, aunque selectiva, hacia el Tercer Mundo; y un activismo en foros multilaterales por medio de alianzas.

${ }^{33}$ La orientación tercermundista sufriría limitaciones por su decisión, hecha también en el gobierno de Geisel (1974-1979), de mantener el crecimiento interno y de consolidar el proceso de sustitución de importaciones mediante la captación de recursos externos, lo que llevó al siguiente gobierno de Figueiredo (1979-1985) a resaltar el entorno brasileño. Cf. Ricardo Sennes, op. cit. 
pacio, a partir de 1987, a la apertura económica interna y a la cuasi alineación con ese país. ${ }^{34}$ Este cambio puede percibirse en los discursos de transmisión de dominio de los ministros de relaciones exteriores del gobierno de Sarney: mientras que Olavo Setúbal marcaba en 1986 la continuidad de los "principios tradicionales" que guiaban la política exterior, Abreu Sodré destacaba en 1990 que su sucesor ya no podría "practicar la diplomacia delimitada por las líneas del mundo en que vivíamos", toda vez que ese mundo iba desapareciendo. ${ }^{35}$ Aun así, Brasil pugnó con vigor por balancear la influencia estadounidense, más allá de la integración regional, al dirigir sus miras hacia China y los países ibéricos, vistos como una oportunidad tanto para evitar el cierre del bloque europeo cuanto para fortalecer las relaciones con los países africanos.

En cuanto a la cultura, la discusión relacionada con el desarrollo era por entonces incipiente -por más que algunos países desarrollados llevaran esa relación por décadas, los debates promovidos por la UNESCO databan de los años setenta. El sentimiento nacional en Brasil sobre la importancia de los factores culturales en los procesos de desarrollo apenas comenzaba a revertirse en los años del gobierno de Sarney, en virtud del proceso de redemocratización interna, concomitante con la reorganización de la estructura gubernamental brasileña como un todo. Como parte de esta reorganización, cabe destacar la creación del Ministerio de Cultura (MinC) ${ }^{36}$

${ }^{34}$ G. R. Barão A diplomacia cultural na política externa do governo Lula: um novo projeto de desenvolvimento nacional (2003-2010), tesis, Departamento de Economia e Relações Internacionais, Porto Alegre, UFRGS, 2012.

${ }^{35}$ F. de M. Barreto, A política externa após a redemocratização, Brasília, Fundação Alexandre de Gusmão (FUnAG), 2012, p. 121.

${ }^{36}$ Hasta entonces subordinada al Ministerio de Educación y Cultura, la cartera adquirió carácter de ministerio en ese año. Bajo el gobierno de Collor, la cultura reduciría su condición a Secretaría, situación revertida en el gobierno de Itamar Franco, en 1992, con la creación del MinC. En 2016, bajo el gobierno interino de Michel Temer, se revivió brevemente el Ministerio de Educación y Cultura, pero por manifestaciones en contra de tal disposición mantuvo su carácter de ministerio adscrito a la cultura. 
y el establecimiento de la Ley Sarney, que introdujo el mecanismo de financiamiento de la cultura por medio de exenciones fiscales ${ }^{37}$ y restableció sus principios en 1991 mediante la Ley Rouanet. ${ }^{38}$ Tanto el MinC como el nuevo modelo de financiamiento servirían también a la política exterior mediante la cooperación interministerial con el MRE.

La discusión sobre diplomacia cultural adquiría importancia a la par. Según Ribeiro, desde que Celso Amorim aceptó la División de Difusión Cultural (DDC) del MRE, en 1978, se inició la revisión y ampliación del concepto de cultura brasileña. En palabras del autor: "sin dejar de lado valores tradicionales, fuimos a buscar en nuestra diversidad [...] los subsidios que necesitábamos para actuar". ${ }^{39}$ De este modo,

${ }^{37}$ La orientación, sin embargo, se derivaba de los gobiernos dictatoriales, cuya diligencia en promover la modernización fue esencial para consolidar la industria cultural brasileña. Los gobiernos vieron en la cultura una estrategia de integración y de seguridad nacional, por lo cual buscaron delinear una política cultural oficial mediante la inversión en infraestructura -creando, por ejemplo, las redes nacionales de televisión- y establecieron nuevos órganos públicos. En tal sentido, la visión mercadológica iba en aumento desde el establecimiento del Consejo Federal de Cultura (1966), cuyo enfoque pretendía la integración, hasta la creación de la Empresa Brasileña de Filmes -Embrafilme (1969) y de la Funarte (1975), cuyo propósito era incentivar la producción y el consumo de la cultura. Cf. N. A. M. Fernandes, "A política cultural à época da ditadura militar", Contemporânea, vol. 3, núm. 1, 2013, en www.contemporanea.ufscar.br/index. $\mathrm{php} /$ contemporanea/article/view/124, consultado el 4.VI.2017, y Barão, op. cit., p. 56.

${ }^{38}$ La ley 8.313/91, conocida como Ley Rouanet, instituyó el Programa Nacional de Apoyo a la Cultura (PRONAC), con la intención de crear tres mecanismos para distribuir los recursos de incentivos a la cultura: el Fondo Nacional de la Cultura (FNC), el Incentivo Fiscal y el Fondo de Inversión Cultural y Artístico (FICART), de los cuales el de mayor utilidad fue el Incentivo Fiscal, mientras que el FICART nunca llegó a implementarse. Cf. MinC, "Histórico", 2016, en www.cultura.gov.br/historico, consultado el 20.IV.2016; "Lei núm. 8.313, de 23 de dezembro de 1991", Presidência da República, Casa Civil, Subchefia para assuntos jurídicos, en http://www2. camara.leg.br/legin/fed/lei/1991/lei-8313- 23-dezembro-1991-363660normaatualizada-pl.html>, consultado el 12.IV.2017.

${ }^{39}$ Ribeiro, op. cit., p. 13. 
además del fomento a la promoción de la cultura brasileña en el exterior, con incentivos para generar programas culturales en las representaciones brasileñas, la cultura se convertía en término común de los discursos presidenciales de Sarney, para quien Brasil no deseaba convertirse en una potencia militar, porque el "poder no es únicamente fuerza, y ésta, sola, no domina la política”. Asimismo, durante un discurso en 1987, consignaba: "a Brasil no le interesa reeditar imperialismos ni ejercer hegemonías. País multicultural y con intereses globales, Brasil busca la interacción entre las culturas y acepta la pluralidad de ideologías y sistemas políticos. Queremos, en realidad, progresar dentro de la paz y la cooperación, a través de lazos horizontales". ${ }^{40}$

En ese camino, el énfasis en la cooperación entre países en desarrollo, característica de la matriz desarrollista, era fundamental. El desajuste matricial influiría en la DC al aducirse que la lengua portuguesa era de capital importancia y que, por tanto, la atención debía dirigirse a los países lusófonos. El Instituto de Pesquisas y Relaciones Internacionales (IPRI), órgano de la Fundación Alexandre de Gusmäo (FUNAG), fundado en 1987 y vinculado al MRE, desempeñó un papel relevante en ese cambio al promover en 1988 el primer Seminario de Relaciones Culturales y Política Exterior, el cual, además de lograr un balance en las actividades promovidas por el MRE, sirvió para discutir temas esenciales en el momento y para analizar las perspectivas de la política cultural brasileña. Ahí se discutió la importancia de elaborar una imagen de Brasil como plural, toda vez que el país no tenía ninguna imagen de antemano, según se comentaba entre los participantes. ${ }^{41}$ Se puntualizó además que, para el

40 MRe, Discursos selecionados do Presidente José Sarney, Brasilia, Fundação Alexandre de Gusmão (FUNAG), 2008, p. 70, en http:/ funag.gov.br/ loja/download/510-Discurso-Selecionado-do-Presidente-Jose-Sarney.pdf, consultado el 6.VIII.2016.

41 Como se ha destacado en la introducción del Cuaderno, el documento buscaba presentar las ideas debatidas, pero no una conclusión de los debates realizados en el Seminario. La argumentación llevada a cabo 
país de la época, "[era] necesario tener opciones. En ese sentido, se subrayó la importancia de la lengua como vehículo privilegiado de difusión cultural. En situación de escasez de recursos, debería haber una concentración en ese medio para poder lograr resultados" ${ }^{42}$ En el documento "Política cultural brasileña en el exterior", ${ }^{43}$ se reafirmó la intención de buscar esa orientación de la diplomacia brasileña, por lo que se sugirió otro camino para alcanzarla:

La diplomacia cultural brasileña opera actualmente confiriendo prioridad a América Latina y África, prioridad que podría ser tal vez reevaluada a la luz de la importancia, para Brasil, de los mercados de países industrializados, así como de mayor dinamismo tecnológico y capacidad financiera de tales países. En relación con ese punto, se discutió la posibilidad de que la difusión cultural brasileña pudiera beneficiarse de la entrada de Portugal a la CEE. Se ponderó que concretar tal posibilidad dependería de que el gobierno brasileño adoptara una línea de actuación más nítida. ${ }^{4}$

En ese sentido, comprendemos que la política cultural brasileña acompañó los cambios efectuados en la PEB: la importancia conferida a las relaciones con América Latina y África dio lugar a un direccionamiento hacia los países considerados desarrollados, sobre todo después de 1987. La posibilidad que surgió a raíz del Seminario parece haberse concretado

en este punto versaba sobre la necesidad de discutir y consolidar una imagen de Brasil, toda vez que, a diferencia de los "clichés" difundidos o combatidos por Francia o por Japón, no había un "postulado”, una imagen que orientara la diplomacia cultural brasileña de entonces. Cf. IPRI, "Seminário sobre Política Externa e Relações Culturais", Cadernos do IPRI, núm. 1, Brasilia, Fundação Alexandre de Gusmão (FUnAG), 1989, p. 19.

42 Idem.

43 El documento determinaba que "los centros receptores prioritarios de la acción cultural [eran] América Latina y África, después Estados Unidos, Europa y, al final, Oriente Medio y Asia” (Ribeiro, op. cit., p. 49). ${ }^{44}$ IPRI, art. cit., p. 20. 
en 1989 en el Primer Encuentro de los Jefes de Estado de Lengua Oficial Portuguesa, cuyo resultado promovió la constitución del Instituto Internacional de la Lengua Portuguesa -futura Comunidad de los Países de Lengua Portuguesa (CPLP). Según el entonces presidente Sarney, la lengua portuguesa

no sólo es un medio de comunicación para nuestra comunidad de naciones; no sólo es un elemento aglutinador para nuestras culturas. [Ella] debe ser, por encima de todo, reflejo y vehículo de movimientos amplios y renovación cultural de nuestros pueblos. Un factor de cultura y, por consiguiente, de desarrollo. ${ }^{45}$

Cabe destacar que el trabajo conjunto del recién creado MinC y del MRE permitió la elaboración del Ajuste Tripartita entre los Ministerios de Relaciones Exteriores, el de Educación y el de Cultura. Firmado en 1987, el IPRI fue considerado durante los debates "el primer paso para lograr una mejor coordinación" entre las políticas culturales internas y exteriores. ${ }^{46}$ Pero, según Ribeiro, "el referido acuerdo en el que radican las razones que lo inspiraron, no llegó a producir resultados dignos de notar". Si bien se multiplicaron las alianzas y actividades culturales en esos últimos años, "sería difícil [...] deducir que ese aumento [correspondiera] a resultados proporcionalmente iguales o superiores" a los que con anterioridad obtenía Brasil. ${ }^{47}$ Según el autor, el área cultural sufría por una gran falta de recursos, y el entonces ministro de Relaciones Exteriores, en exposición hecha al Presidente en el año 1987, advertía sobre la insuficiencia de recursos disponibles para el área cultural "hasta para cubrir los gastos sumados para mantener los Centros de Estudios Brasileños en funcionamiento, de los agregados culturales, de las activida-

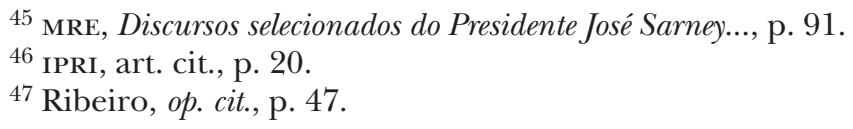


des del electorado y de las contribuciones a organismos internacionales", es decir, para hacer posible que el programa de promoción cultural elaborado por el MRE pudiera llevarse a cabo. ${ }^{48}$

Es importante señalar, sin embargo, que la cooperación interministerial permitía otro medio de financiamiento: el uso de la Ley Sarney para proyectos en el exterior. Y, más allá de una alternativa, el tratamiento que se daba a la cultura coincidía con la propuesta hecha en el Seminario de 1988 que sugería "evitar, aun en eventos organizados por órganos gubernamentales, el carácter de «muestra oficial de cultura», optándose por eventos de carácter plural e independientes". ${ }^{49}$ Esto es, la cultura dejaba de tenerse por una cuestión de Estado, como sucedió durante el régimen dictatorial, y se dirigía a la sociedad civil, aunque con un sesgo mercadológico. Además, la falta de recursos no se veía como causa, sino como consecuencia de la falta sistemática de planeación y coordinación entre los órganos responsables. Esta carencia, a su vez, se derivaba de una "perspectiva de trinchera" 50 en asuntos relacionados con la DC, que eran tratados de forma "puntual". Era necesario, entonces, que el Estado pasara por un proceso de reflexión sobre las políticas culturales, promoviendo un trabajo concreto de planeación y de estructuración de iniciativas para que la diplomacia cultural se percibiera en su concepción más amplia de instrumento para la inserción externa del país y la consolidación de su identidad. ${ }^{51}$

Conforme aseguran los teóricos de política exterior mencionados en el primer capítulo de este artículo, al inicio de los años noventa, la PEB entraba en un periodo de posicionamiento menos activo a causa del Estado. En el plano cultural interno, al establecerse la Ley Rouanet y al predominar el financiamiento indirecto mediante exenciones

\footnotetext{
48 Ibidem, p. 89.

49 IPRI, art. cit., p. 21.

${ }^{50}$ Ibid., p. 18.

${ }^{51}$ Ribeiro, op. cit.
} 
fiscales ${ }^{52}$-una orientación que aprovechó el gobierno de Fernando Henrique Cardoso (1995-2002) con la ampliación del uso de este mecanismo-,${ }^{53}$ surgieron las críticas a la posición del Estado como mero financiador, pero mermado en poder de decisión o de planeación. Por ello, partiendo de la idea de que también en la diplomacia cultural hubo un cambio, de una participación estatal menos vigorosa a una más activa, analizamos a continuación la forma en que se retomó la DC después del gobierno de Sarney.

\section{LA DIPLOMACIA CULTURAL EN LA POLÍTICA EXTERIOR DE Lula da Silva}

A partir de la redemocratización, como se vio con anterioridad, la idea de la cultura como herramienta de política exterior pasó por diversas modificaciones, particularmente en lo que concierne a entender el papel del Estado y del mercado en promover este tipo de diplomacia. Durante el periodo de "paradigma normal" 54 de la década de los años noventa, el Estado dejó de tener una función relevante como articulador de la diplomacia cultural, con lo que el mercado se convirtió en factor preponderante. Durante el gobierno de Lula

${ }^{52}$ La Ley núm. 8.313 de 1991 instituyó el Programa Nacional de Incentivo a la Cultura-PronaC, a partir de tres bases: el Fondo Nacional de Cultura, con financiamiento directo; los Fondos de Inversión Cultural y Artística, destinados a la infraestructura y a la industria cultural; y los incentivos fiscales, que permiten la deducción de hasta $100 \%$ de los valores donados o utilizados para patrocinar proyectos culturales por personas físicas o jurídicas. Sin embargo, los fondos nunca se implementaron y predominó el financiamiento indirecto por medio de exenciones fiscales, confundiéndose con la propia ley, lo que se vio reforzado con la Ley del Audiovisual, de 1993, también con base en incentivos fiscales. Cf. G. M. Salgado, L. S. Pedra y R. dos S. Caldas, "As políticas de financiamento à cultura: a urgência de uma reforma”, en A. A. C. Rubim (org.), Políticas culturais no governo Lula, Salvador, EDUFBA, 2010, pp. 87-110.

${ }^{53}$ Silva, art. cit.

${ }^{54}$ Cervo y Bueno, op. cit. 
(2003-2010), los efectos nocivos de la falta de participación reclamaron finalmente la atención. Amado Cervo nombraría esta etapa como "Estado logístico", en el cual la institución retoma el papel de articuladora de la política exterior, esta vez junto a la sociedad, en un intento por satisfacer tanto los intereses sociales y políticos de autonomía del país en el sistema internacional, como los intereses del mercado. Para ello, el Estado brasileño empezó a invertir en la ampliación de temas importantes para el desarrollo del país en política exterior. Es en ese marco que este análisis entiende la cultura como herramienta importante para la PEB.

Desde los años ochenta, el mundo atestiguó el cambio en la percepción económica de la cultura. Diversos países considerados desarrollados se beneficiaron de las ventajas comerciales de la globalización para asociar sus productos culturales con las leyes de la propiedad intelectual, por medio de patentes y otros instrumentos proteccionistas, incorporando innovaciones a los artículos culturales y actuando de modo monopólico. Acciones de este tipo dentro del GATT y de la omc son, aun en la actualidad, ejemplos claros de que cierto tipo de cultura puede favorecerse en un sistema de "libre mercado". Si bien teóricamente éstos se consideran intereses globales, en palabras de Lessa acaban reflejando "los patrones de propiedad intelectual de los países industrializados [en forma pionera], inclusive en la definición de las formas de expresión cultural de pasividad en la protección de derechos autorales, sugieren una visión monolítica de cultura". ${ }^{55}$

Al entrar en un nuevo siglo, la percepción de la unipolaridad de Estados Unidos era cada vez más débil con el surgimiento de las naciones llamadas emergentes. Para Cervo y Bueno, estas últimas intentaban conseguir un mayor espacio en el ámbito de la globalización, amén de criticar las asimetrías del orden mundial vigente. ${ }^{56}$ En esas circunstancias

${ }^{55}$ Art. cit., pp. 253-254.

${ }^{56}$ Cervo y Bueno, op. cit. 
resurgía la lógica Norte-Sur en el si, en que los países emergentes avizoraban posibilidades de ampliar su influjo global mediante un contacto más cercano entre sus culturas a partir del acceso a la información, la facilidad de transportación y los estímulos a la educación y al turismo, que generarían diversas formas de expresión cultural. Así, la diversidad cultural que estimulaba la multiculturalidad y cuestionaba el efecto de homogeneidad comenzó a ser tema de debate en foros multilaterales -con énfasis para las Naciones Unidas (ONU) - y, principalmente, en foros regionales. ${ }^{57}$ Según Leila Bijos y Verónica Arruda, el gobierno y la sociedad brasileña poco a poco empezaron a percibir que las poblaciones más pobres debían conocer qué era la cultura y la identidad, por lo cual era necesario que el desarrollo les ofreciera la posibilidad de recibir también un usufructo de los beneficios de la cultura. ${ }^{58}$

El cambio de idea dio margen al surgimiento de una nueva percepción del Estado, como apuntan Cervo y Bueno: "el propósito de democratizar la globalización y distribuir los beneficios del orden internacional requiere del reforzamiento del Estado como negociador y el sustento logístico de los intereses nacionales y alianzas con países emergentes de idénticos objetivos". ${ }^{59}$ Se retomaba entonces la visión de que era necesario revisar las reglas del sistema internacional para incluir esas nuevas perspectivas en las que Brasil debía participar y propiciar así un ambiente favorable para sus propósitos. ${ }^{60}$

Esa nueva estrategia de inserción externa tiene su base, según Cervo, en dos fundamentos: el primero se relaciona con la idea de desarrollo nacional, asentada en el equilibrio entre crecimiento económico y justicia/inclusión social; el

${ }^{57}$ Lessa, art. cit.

58 "A diplomacia cultural como instrumento de política externa brasileira”, Revista Dialogos, Brasilia, vol.13, núm.1, 2010, pp. 33-53, en http:/ / portalrevistas.ucb.br/index.php/RDL/article/viewFile/2912/1824, consultado el 23.V.2016.

${ }^{59}$ Op. cit., p. 528.

${ }^{60} \mathrm{Id}$. 
segundo refiere al entendimiento del si como multipolar, por lo cual se daría espacio a los países del Sur Global en el debate de las reglas internacionales. ${ }^{61}$ Tales fundamentos influyeron en la РEB y se reflejaron en lo regional, por ejemplo en la diplomacia cultural de Brasil, que comenzó a utilizar mecanismos regionales e interregionales para alcanzar un desarrollo autónomo, ${ }^{62}$ como se hace evidente en el siguiente fragmento de un discurso de Lula:

Tenemos que hacer un Mercosur democrático, participativo [...]. Por ello es necesario fortalecer también las agendas política, social y cultural del Mercosur, darles una dimensión humana. Precisamos conocernos mejor, crecer juntos para garantizar apoyo duradero al proceso de integración. Daremos importancia a la construcción de instituciones comunes, de políticas sociales articuladas, de asociación en el área educacional y cultural dentro del bloque, para que pueda florecer una verdadera identidad de los ciudadanos de nuestros países con el Mercosur. ${ }^{63}$

La participación del Estado en la promoción e inversión en cultura es esencial desde la perspectiva de desarrollo, así como la acción de la sociedad en su producción. Según Bijos y Arruda, la política exterior cultural de Lula tuvo tres dimensiones: 1) simbólica, que tiende a atribuir a los bienes culturales el nivel de patrimonio brasileño; 2) económica, en un intento por explorar sus beneficios económicos y 3)

61 "Política exterior e relações internacionais do Brasil: enfoque paradigmático", Revista Brasileira de Política Externa, vol. 46, núm. 2, 2003, pp. 5-25, em www.scielo.br/pdf/rbpi/v46n2/v46n2a01.pdf, consultado el 17.V.2016.

${ }^{62}$ F. Soulé-Kohndou, "L'action culturelle Sud-Sud du Brésil a travers les clubs de puissances emergentes: fonctions et usages", Cahiers des Amériques latines, vol. 80, núm. 2, 2015, pp. 31-48.

${ }^{63}$ Mre, Discursos selecionados do Presidente Luiz Inácio Lula da Silva, Brasilia, Fundação Alexandre de Gusmão (FUNAG), 2008, pp. 28-29, en http: //funag.gov.br/loja/download/505-discursos_selecionados_lula.pdf. 
ciudadana, que utiliza objetivamente la cultura como forma de desarrollo social. Así, el Estado asumió la posición de planificador y promotor de las iniciativas culturales -buscando abrir espacios para la cultura como un derecho social de todos los brasileños- en lugar de ser únicamente patrocinador o ejecutor de proyectos con alta dificultad de marketing, ${ }^{64}$ lo que queda en evidencia incluso por la creación de mecanismos institucionales dentro del MinC y del MRE.

De esa forma, las discusiones promovidas durante los gobiernos de Lula llevarían a buscar alternativas tipo Rouanet, a formular el Plan Nacional de Cultura (2010-2020), a reformular el Ministerio de Cultura ${ }^{65}$ y a la creación de una política de edictos que permitía, a pesar del predominio del mecanismo indirecto, el financiamiento de sectores prioritarios, incluidos proyectos relacionados con la cooperación sudamericana. ${ }^{66}$ Para Cervo y Bueno, en su obra citada, la PEB comenzó a hacer sus sociedades universales sin abandonar las relaciones tradicionales, las cuales incluso incrementó en los países del Sur Global. Así lo decía Lula: "Brasil puede y debe tener un proyecto de desarrollo que sea al mismo tiempo nacional y universalista". ${ }^{67}$ Se dio una ampliación, pues, tanto de las sociedades internacionales brasileñas, como del entendimiento del desarrollo, visto éste como cre-

${ }^{64}$ Serviço Social da Indústria (SESI) y Departamento Nacional (DN), A estrutura das leis de incentivo à cultura: Parte 1, Brasilia, SESI-DN, 2007, en http://www3.sesi.org.br/Programas/src_cultura/Vol_04_P1.pdf, consultado el 1.V.2016.

${ }^{65}$ J. H. Bezerra y R. G. Weyne, "Política Cultural no Brasil Contemporâneo: percursos e desafios", en IV Seminário Internacional - Políticas Culturais, Rio de Janeiro, 2013, en http:/ / culturadigital.br/politicaculturalcasa deruibarbosa/files/2013/11/Jocastra-Holanda-Bezerra-et-alii.pdf, consultado el 3.VI.2017.

66 L. Calabre, "Política Cultural em tempos de democracia: a era Lula”, Revista do Instituto de Estudos Brasileiros, núm. 58, 2014, pp. 137-156, en www.scielo.br/scielo.php?pid=S0020-38742014000100008\&script=sci_ abstract\&tlng=pt, consultado el 1.VI.2017.

67 MRe, Discursos selecionados do Presidente Luiz Inácio Lula da Silva..., p. 13 . 
cimiento humano y, por tanto, propicio para abarcar varias áreas del conocimiento, entre ellas la cultura. Como consigna Folashadé Soulé-Kohndou, la tentativa de expansión de la DC brasileña se ofreció como forma de desarrollo autónomo multiplicador y no como un proyecto imperialista de superposición de otras culturas. Para eso fue necesario estimular la creación de un nuevo referencial cultural con base en la cooperación de países del Sur. Ejemplo de ello puede ser el IBAS, que tenía como marco cultural el intercambio de conocimientos y buenas prácticas, con el propósito de erigir una identidad colectiva. ${ }^{68}$ Por lo mismo, llama la atención la posición del Servicio Social de la Industria (SESI), para el cual la cultura debería "ser considerada como fuente de riqueza y generadora de empleos, y la diversidad y la pluralidad cultural, la memoria histórica, la creación artística y la comunicación humana, como elementos indispensables para el desarrollo del hombre"; 69 es decir la creación de una identidad colectiva también debería acompañarse de intereses de mercado.

En el MRE, la cultura obtuvo importancia en esa época, al igual que el sector internacional obtuvo fuerza en el MinC. El anhelo de Amorim, ministro de Relaciones Exteriores de Brasil en el periodo de Lula, residía en abrir mercados; para el país era imprescindible ampliar su base de productos con tecnología avanzada y, en ese sentido, la industria cultural podía ser una gran aliada en el plano de desarrollo. Según él, Brasil, país de la moda, del futbol, de la música popular y del cine, tenía que fundar su propia industria creativa y fortalecer su base tecnológica, expansión que beneficiaría a la economía, la política y la cultura. ${ }^{70}$

68 Soulé-Kohndou, art. cit.

${ }^{69}$ SESI y DN, op. cit., p. 8.

70 Mre, Resenha de Política Exterior do Brasil, Brasilia, Gráfica do Ministério das Relações Exteriores, núm. 92, año 30, 2003, en www.itamaraty. gov.br/images/ed_biblioteca/resenhas_peb/Resenha_N92_1Sem_2003. pdf, consultado el 10.V.2016. 
Al mismo tiempo, se hizo un intento de exportar a los países del Norte Global una imagen de Brasil que proyectara gran potencia hacia el futuro para consolidar la posición de país emergente. Entre las iniciativas brasileñas con ese propósito, podemos citar tres frentes de trabajo: 1) alianza con asociaciones tradicionales que buscaban atraer inversiones turísticas y tecnológicas, como el "Año de Brasil en Francia", llevada a cabo por el MRE -generó un incremento de 54 millones de dólares en ingresos turísticos de Brasil-, ${ }^{71}$ y como el acuerdo Brasil-Japón para implementar la TV digital -que permitió el fomento de una importante asociación cultural y tecnológica; ${ }^{72}$ 2) asociaciones transregionales, como grupos de trabajo del IBAs73 -que promueve la creación de centros culturales y financiamiento colectivo de una identidad colectiva-y de la CPLP - que busca una aproximación cultural por medio del idioma, representada por la reforma ortográfica ratificada por Brasil en 2008- ${ }^{74}$ para la creación de la Universidad de la Integración de la Lusofonía Afro-Brasileña (UNILAB) y para el apoyo económico en el incremento de la agenda de exportación brasileña para África; 3) asociaciones regionales, como con el Mercosur -el más importante en sentido de identidad cultural por medio de intercambios académicos, creación de la Universidad Federal de la Integración Latinoamericana (UNILA), inversión en infraestructura, aproximación económica y lingüística. ${ }^{75}$

La nueva percepción trajo consigo la idea de que el desarrollo económico necesitaba representar un aumento del bienestar social, promovido también por el estímulo a la cul-

${ }^{71}$ Bijos y Arruda, art. cit.

72 Barão, op. cit.

73 Soulé-Kohndou, art. cit.

74 “Acordo ortográfico só entrará em vigor em 2016”, Portal Brasil, 2014, en www.brasil.gov.br/educacao/2014/12/acordo-ortografico-so-en trara-em-vigor-em-2016, consultado el 10.VIII.2016.

75 Fortalecida por la Ley núm. 11.161/2005, que estableció la inclusión de la lengua española como obligatoria en la currícula escolar de Brasil en 2010. 
tura. El discurso relacionado con las cuestiones sociales y con la autonomía de Brasil en el escenario internacional comenzó gradualmente a integrar el proyecto cultural brasileño, incluyéndolo en las orientaciones del MRE, sobre todo a causa del entonces ministro Celso Amorim, y del MinC, y del gran apoyo de los ministros de cultura Gilberto Gil y Juca Ferreira. Así, la diversidad cultural se convirtió en una forma de defender la identidad brasileña en el exterior. ${ }^{76}$

El MinC, un gran articulador en el fomento de la producción cultural interna, actuó conjuntamente con el Estado brasileño en la organización y el desarrollo de las acciones culturales e introdujo reformas institucionales durante el periodo de Lula ${ }^{77}$ con vistas a establecer justicia e inclusión social. Para motivar la democratización del acceso a la cultura, el MinC impulsó la participación de la sociedad civil, mediante concurso de admisión en el ministerio, en seminarios, cámaras sectoriales y conferencias, según Antonio Rubim, que culminó en la Conferencia Nacional de Cultura. ${ }^{78} \mathrm{La}$ constitución del Plan Nacional de Cultura y la creación del Sistema Nacional de Información e Indicadores Culturales (SNIIC), en 2004, evidenciaron la participación del Estado en las actividades culturales, así como la importancia de la cultura en sus acciones de política exterior.

Entre los temas internacionales promovidos por el MinC, son de mencionar: la difusión cultural brasileña en el ámbito internacional; el apoyo a los productos brasileños en el exterior; la integración regional; la elaboración de estrategias de internacionalizar el arte y la cultura brasileños; la institución

76 Barão, op. cit.

${ }^{77}$ En 2003, 2004, 2006 y 2009. "Decreto núm. 4.805, de 12 de agosto de 2003”, Presidência da República, Casa Civil, Subchefia para assuntos jurídicos, en www.planalto.gov.br/ccivil_03/decreto/2003/d4805.htm, consultado el 4.V.2016.

78 "Políticas culturais do governo Lula / Gil: desafios e enfrentamentos”, Intercom. Revista Brasileira de Ciências da Comunicação, vol. 31, núm. 1, 2008, pp. 183-203, en https:/ / repositorio.ufba.br/ri/bitstream/ri/1242/1/ Antonio\%20Albino\%20Canelas\%20Rubim3.pdf, consultado el 30.IV.2016. 
de una agencia de cooperación cultural internacional; el énfasis puesto en los países del Sur; la difusión virtual de las actividades del ministerio; la inserción de las productoras de bienes culturales en el mercado internacional y el fomento al intercambio de estudiantes y de profesionales de la cultura. ${ }^{79}$ Según el artículo citado de Bijos y Arruda, en 2010 el MinC contaba con 21 unidades internacionales: 12 en el continente americano, 3 en Europa y 6 en África. Durante los mandatos de Gil y Ferreira, este ministerio también buscó estimular, como forma de desarrollo, que la cultura llegara a grandes sectores sociales. Una de las principales acciones de ese primer momento fue la creación de trescientas representaciones en comunidades de alto riesgo social. ${ }^{80}$

Las relaciones del MinC con la sociedad civil se dieron por medio del fomento a proyectos culturales, pero también, y principalmente, por incentivos fiscales a proyectos con impronta cultural. Entre 2003 y 2005, años en que se comenzó con esa nueva estrategia, el gobierno federal amplió el gasto público para la cultura de $\mathrm{R} \$ 2.4$ billones a $\mathrm{R} \$ 3.1$ billones, aproximadamente, con lo que se aumentó también su participación en el gasto público porcentual de $14.4 \%$ a $16.7 \% .{ }^{81}$ Los proyectos aprobados por la Ley Rouanet entre 2003 y 2004 ascendieron de 4016 a 5 748, pero se observó una caída de $20.42 \%$ en esos incentivos, comparándolos con los del periodo de Fernando Henrique Cardoso (FHC). ${ }^{82}$ Los pro-

79 “Lei núm. 12.343, de 2 de dezembro de 2010”. Presidência da República, Casa Civil, Subchefia para assuntos jurídicos, en www.planalto.gov.br/ ccivil_03/_ato2007-2010/2010/lei/112343.htm, consultado el 1.V.2016.

${ }^{80}$ Barão, op. cit.

${ }^{81}$ Estudos e Pesquisas, Sistema de Informações e Indicadores Culturais (2003-2005), Río de Janeiro, IBGE, 2007 (Informação Demográfica e Socioeconômica, 22), en http://biblioteca.ibge.gov.br/visualizacao/livros/liv37306. pdf, consultado el 29.IV.2016.

82 SESI y DN, op. cit. Como señala Antonio A. Canelas Rubim, la causa se debe al hecho de que el Estado comenzó a invertir más en acciones gubernamentales, en detrimento de los incentivos fiscales concedidos a empresas privadas que invertían en proyectos culturales -caso de la Ley Rouanet-, lo que equivale, precisamente, a un cuello de botella para la 
yectos ascendieron en 2010 a 7 926, concentrados en áreas como las artes escénicas, artes integradas, artes visuales, audiovisuales, humanidades, museos y memoria, música y patrimonio cultural. ${ }^{83}$

La articulación entre el MinC y el Mre se dio por vía institucional. El MinC abrió una Dirección de Relaciones Internacionales, responsable de coordinar la participación del ministerio en organismos y eventos internacionales relacionados con la cultura. El Itamaratí, en cambio, contó con un Departamento Cultural que abarcaba cinco áreas: promoción de la lengua portuguesa (DPLP), difusión cultural (DODC), promoción audiovisual (DAV), asuntos multilaterales (DAMC) y educación (DCE). Además, los ministros de cultura también desempeñaron un papel fundamental en la estrategia de inserción de Brasil en el exterior al actuar conjuntamente con el MRE en algunos acontecimientos de cobertura internacional. La difusión de la información fue tema de gran importancia internacional que abarcaba tanto las carteras de cultura, como de relaciones internacionales y de combate a la pobreza. Fue bajo el liderazgo de Gilberto Gil, en la Cúpula Mundial de la Sociedad de la Información en 2005, cuando surgió el consenso en que se precisaba de una sociedad de información inclusiva y en que se consolidó la idea de que la tecnología de la información y de las comunicaciones es un medio de desarrollo. Además, surgió la garantía de que la gestión de la red mundial de la Internet fuera internacional, en reconocimiento a la propuesta brasileña de la gobernanza de la Internet. ${ }^{84}$

multiculturalidad, porque estimulaba la concentración de la inversión en grandes empresas. Para Rubim, entonces, la cuestión de la exención fiscal no se solucionó completamente en el gobierno de Lula, pues la ley no se modificó, lo que hasta hoy representa un problema.

${ }^{83}$ Salicnet, en www.sistemas.cultura.gov.br/comparar/salicnet/salicnet.php, consultado el 20.IV.2017.

84 Mre, Resenha de Política Exterior do Brasil, Brasilia, Gráfica do Ministério das Relações Exteriores, núm. 97, año 32, 2005, en www.itamaraty. gov.br/images/ed_biblioteca/resenhas_peb/Resenha_N97_2Sem_2005. pdf, consultado el 18.V.2016. 
Así fue como la diplomacia cultural de Lula entendió el inicio de la transición hacia una nueva matriz de "Estado logístico", en la cual el Estado recuperaba su función como articulador de políticas públicas y en la cual se dio una fuerte conexión entre las políticas interna y exterior, con vista a la universalización de las asociaciones internacionales y a la multiculturalidad en el si, al tiempo que en el ámbito nacional se contribuía a la democratización, inclusión social y desarrollo del país.

\section{Consideraciones Finales}

Es notorio que el aspecto cultural no tiene -ni ha tenido a lo largo de la historia- la misma importancia dentro de los Estados en la SI. La globalización parece reproducir, también en el campo cultural, divisiones y exclusiones a causa de la concentración de la producción y del consumo de la cultura en ciertos países del mundo. Por lo menos, de entre las demás esferas de la política exterior, es evidente que la cultura disfruta de un espacio semejante. En el campo académico de las Relaciones Internacionales no es diferente. Esta tarea es todavía muy inclusiva y compleja, muchas veces subestimada en las investigaciones que analizan las dimensiones de poder de los Estados.

En contra de esa tendencia, este artículo buscó destacar el valor de la cultura para la PEB, así como la articulación de la cultura con otros ámbitos, pues su complementación mutua promueve una acción más asertiva y coherente del Estado en favor del interés nacional. Al final, este aspecto también puede ser determinante en las disputas por el poder en el sistema internacional, toda vez que el valor conferido a la cultura nacional es capaz de afirmar la presencia de una nación en el exterior, evitando o mitigando el dominio epistemológico, así como de influir en la consolidación de su identidad nacional y en su desarrollo como Estado. De ahí la importancia esencial de estudiar el tema con ma- 
yor detenimiento, sobre todo cuando se trata de un país emergente como Brasil.

A partir del estudio del significado de la diplomacia cultural se entendió que tal instrumento ha servido a los intereses de Brasil en favor de su desarrollo. Como se ha demostrado a lo largo de este análisis, la DC, dependiendo de los factores internos y externos que influyeron en su conformación, tuvo diferentes funciones a lo largo del tiempo como parte del proyecto de desarrollo brasileño. Si en algunos momentos el Estado se abstuvo de participar activamente en el proceso de desarrollo y divulgación de la cultura brasileña, en otros desempeñó un papel preponderante. Después de señalar las diferentes circunstancias en que hubo una participación relativamente más pujante del Estado en la formulación de las directrices de la DC a partir de la redemocratización, el presente estudio corroboró su hipótesis de que los gobiernos de Lula y Sarney pasaron por dos momentos de transición matricial de la PEB en que el Estado desempeñó precisamente esta función.

Con la transición matricial que ocurría durante el gobierno de Sarney (1985-1990), se inició la búsqueda de una imagen plural del país por medios más mercadológicos que la cultura debía asumir. Además, en un ámbito de crisis internas, promover la lengua portuguesa parecía un procedimiento central de la diplomacia cultural; por ello, la creación del Instituto Internacional de la Lengua Portuguesa permitió el surgimiento de una identidad entre las disputas del rumbo de la PEB y, en consecuencia, de este aspecto. Si bien el debate recién estaba surgiendo, y la cultura todavía se veía como algo menos importante en relación con las demás preocupaciones de la PEB, lo que se reflejaba era, además del bajo presupuesto del sector cultural, la falta de planeación para mejorar sus condiciones. Con ello, la ampliación de la presencia del mercado mitigó el poder de decisión y de planeación del Estado en la DC y fomentó un modelo limitado de financiamiento.

Después de disminuir la presencia del Estado en la PEB, el mandato de Lula (2003-2010) se identificó como marco de la 
siguiente transición matricial, momento susceptible de comparación con la época anterior por el carácter común en la definición de la participación estatal, que tuvo más alcance al incorporar el papel articulador de este actor en la DC, aliándose al mercado y a la sociedad civil. Durante los años de la primera década del 2000, periodo de consolidación democrática, se buscó superar las desigualdades sociales que impedían el desarrollo. Es importante mencionar el incentivo a las industrias cultural y tecnológica del país, que tuvieron un papel decisivo en el acceso del país y de su propia sociedad a las tecnologías de la información. En el ámbito interno, la cultura se iba estableciendo como un sector estratégico del desarrollo nacional, las funciones del Estado se fortalecían en su organización y la diplomacia cultural adquiría un cuño más popular. En lo atinente a la política exterior, en un ámbito de cuestionamiento sobre la homogeneidad inherente a la globalización, la cultura también pasó a ser un instrumento de defensa frente a la democratización en el sistema internacional, convirtiéndose en un mecanismo de identificación y de aproximación entre los países del llamado Sur Global.

Es por ello que el gobierno de Lula, al igual que el de Sarney en un primer momento, demostró interés en promocionar la cultura brasileña en los países de América Latina y los Países Africanos de Lengua Oficial Portuguesa (PALOp) -además de reivindicar la lengua portuguesa y estimular la concesión de becas para su estudio-y fue más allá al expandir tal política a los demás países africanos y al Oriente Medio, es decir, al Sur Global. Con todo, no se abandonaron las asociaciones estratégicas con los países del Norte, puesto que se buscó también, mediante la cultura, absorber tecnologías para difundir la información y transmitir una imagen favorable del país, además de atraer inversiones de estas naciones, con lo que se puso en evidencia el carácter armónico de la PEB. La DC, por tanto, adquiría importancia relevante en la PEB al contribuir en la búsqueda de correspondencia entre el discurso y la práctica y entre la imagen internacional y la condición interna del país. 
Se concluye, para este contexto, que la diferencia sugerida al inicio del trabajo entre ambos momentos reside principalmente en la percepción de la cultura como herramienta de la PEB. Mientras que en Sarney se observó una posición más tímida de la diplomacia cultural, en Lula se percibió un punto de inflexión en ese sentido, pues la cultura pasó a tenerse por herramienta de combate en contra de la desigualdad y por fuerte mecanismo de los países emergentes en el empeño de democratizar el sistema internacional, haciéndose imprescindible, por tanto, para el desarrollo de Brasil. Sin embargo, aún es precipitado afirmar que la DC haya conquistado un espacio consolidado en la PEB, sobre todo si se considera la reciente inestabilidad política susceptible de representar un nuevo periodo de transición. Por ello, el estudio de la DC brasileña todavía continuará avanzando como tema de futuros análisis de política exterior del país.

\section{Bibliografía}

“Acordo ortográfico só entrará em vigor em 2016", Portal Brasil, 2014, en www.brasil.gov.br/educacao/2014/12/acordo-ortogra fico-so-entrara-em-vigor-em-2016

Arndt, Richard T., The First Resort of Kings: American Cultural Diplomacy in the Twentieth Century, Washington, D. C., Potomac Books, 2005.

Avila, Carlos Federico Domínguez, "O Brasil frente ao conflito regional na América Central: oposição ao intervencionismo e apoio à solução negociada, justa, equilibrada e duradoura (1979 - 1996)", Revista Brasileira de Política Internacional, vol. 46, núm. 1, 2003, pp. 66-93.

Barão, Giulia Ribeiro, A diplomacia cultural na política externa do governo Lula: um novo projeto de desenvolvimento nacional (2003-2010), tesis, Departamento de Economia e Relações Internacionais, Porto Alegre, UFRGS, 2012.

Barreto, Fernando de Mello, A política externa após a redemocratização, Brasilia, Fundação Alexandre de Gusmão (FUNAG), 2012. 
Bezerra, Jocastra Holanda y Rachel Gadelha Weyne, "Política Cultural no Brasil Contemporâneo: percursos e desafios", en $I V$ Seminário Internacional - Políticas Culturais, Rio de Janeiro, 2013, en http://culturadigital.br/politicaculturalcasaderuibarbosa/ files/2013/11/Jocastra-Holanda-Bezerra-et-alii.pdf

Bijos, Leila y Verônica Arruda, "A diplomacia cultural como instrumento de política externa brasileira”, Revista Dialogos, Brasília, vol.13, núm. 1, 2010, pp. 33-53, en http://portalrevistas.ucb. br/index.php/RDL/article/viewFile/2912/1824

Calabre, Lia, "Política Cultural em tempos de democracia: a era Lula”, Revista do Instituto de Estudos Brasileiros, núm. 58, 2014, pp. 137-156, en www.scielo.br/scielo.php?pid=S002038742014000100008\&script=sci_abstract\&tlng=pt

Castro, Henrique Carlos de, "Cultura política, democracia e hegemonía”, en Gramsci e o Brasil, 2000, en www.acessa.com/grams ci/?page=visualizar\&id $=102$

Cepaluni, Gabriel y Tullo Vigevanni, "A Política Externa de Lula da Silva: a estratégia da Autonomia pela Diversificação", Contexto Internacional, vol. 29, núm. 2, 2007, pp. 273-335.

Cervo, Amado, "Política exterior e relações internacionais do Brasil: enfoque paradigmático", Revista Brasileira de Política Externa, vol. 46, núm. 2, 2003, pp. 5-25, em www.scielo.br/pdf/ rbpi/v46n2/v46n2a01.pdf

y Clodoaldo Bueno, História da Política Exterior do Brasil, Brasilia, EdUnB, 2008.

Chakraborty, Kishore (ed.), Cultural Diplomacy Dictionary, Berlín, Institute for Cultural Diplomacy, 2013, en www.cd-n.org/content/pdf/Cultural_Diplomacy_Dictionary.pdf

Córdova, Arnaldo, La revolución y el estado en México, México, Era, 1989.

Cox, Robert W., Production, power and world order: Social forces in the making of history, Nueva York, Columbia University Press, 1987.

"Decreto núm. 4.805, de 12 de agosto de 2003", Presidência da República, Casa Civil, Subchefia para assuntos jurídicos, en www.planalto.gov.br/ccivil_03/decreto/2003/d4805.htm

Diniz, Eli, "Desenvolvimento e Estado desenvolvimentista: tensões e desafios da construção de um novo modelo para o Brasil do 
século xxi”, Revista de Sociologia e Política, vol. 21, num. 47, 2013, pp. 9-20.

Dumont, Juliette y Anaís Flétchet, "Pelo que é nosso!: a diplomacia cultural brasileira no século xx", Revista Brasileira de História, vol. 34, num. 6, 2014, en www.scielo.br/pdf/rbh/v34n67/a10v 34n67.pdf

Estudos e Pesquisas, Sistema de Informações e Indicadores Culturais (2003-2005), Río de Janeiro, IBGE, 2007 (Informação Demográfica e Socioeconômica, 22), en http://biblioteca.ibge.gov.br/visualizacao/livros/liv37306.pdf

, Sistema de Informações e Indicadores Culturais (2007-2010), Río de Janeiro, IBGE, 2013 (Informação Demográfica e Socioeconômica, 31), en http://biblioteca.ibge.gov.br/visualizacao/livros/ liv65974.pdf/

Fausto, Boris, História do Brasil, São Paulo, Editora da Universidade de São Paulo, 1995.

Fernandes, Natalia Ap. Morato, "A política cultural à época da ditadura militar", Contemporânea, vol. 3, núm. 1, 2013, en www. contemporanea.ufscar.br/index.php/contemporanea/article/view/124

Fonseca, Carmen, "A Política Externa Brasileira da Democracia. O paradoxo da mudança na continuidade?”, Relações Internacionais, núm. 29, 2011, en www.scielo.mec.pt/scielo.php?script= sci_arttext\&pid=S1645-91992011000100003

Hall, Stuart, "The centrality of culture: notes on the cultural revolutions of our time", en Kenneth Thompson (ed.), Media and cultural regulation, Thousand Oaks, Sage Publications, 1997, pp. 208-238, en www.henryagiroux.com/links/centrality of culture.pdf

IPRI: Instituto de Pesquisa de Relações Internacionais, "Seminário sobre Política Externa e Relações Culturais", Cadernos do IPRI, núm. 1, Brasilia, Fundação Alexandre de Gusmão (FUNAG), 1989.

"Lei núm. 8.313, de 23 de dezembro de 1991", Presidência da República, Casa Civil, Subchefia para assuntos jurídicos, en http:/ / www2.camara.leg.br/legin/fed/lei/1991/lei-8313-23-dezembro1991-363660-normaatualizada-pl.html 
"Lei núm. 12.343, de 2 de dezembro de 2010". Presidência da República, Casa Civil, Subchefia para assuntos jurídicos, en www. planalto.gov.br/ccivil_03/_ato2007-2010/2010/lei/112343. htm

Lessa, Mônica Leite, "Bens e Serviços Culturais: o lugar do Brasil na Cena Internacional (2001-2006)", en $32^{\circ}$ Encontro Anual da Anpocs. GT10 Cultura, Economia e Política, en http://www.anpocs.com/index.php/papers-32-encontro/gt-27/gt10-21/23 83-monicalessa-bens/file

y Rogelio Suppo (orgs.), A quarta dimensão das Relações Internacionais: a dimensão cultural, Río de Janeiro, Contra Capa, 2012.

"Medida provisória núm. 726, de 12 de maio de 2016", Presidência da República, Casa Civil, Subchefia para assuntos jurídicos, en www.planalto.gov.br/ccivil_03/_Ato2015-2018/2016/Mpv/ mpv726.htm

“Medida provisória núm. 728, de 23 de maio de 2016”, Presidência da República, Casa Civil, Subchefia para assuntos jurídicos, en www.planalto.gov.br/ccivil_03/_Ato20152018/2016/Mpv/ mpv728.htm\#art5

MinC: Ministério da Cultura (Brasil), "Histórico", 2016, en www. cultura.gov.br/historico

MRE: Ministério das Relações Exteriores (Brasil), Resenha de Política Exterior do Brasil, Brasilia, Gráfica do Ministério das Relações Exteriores, núm. 92, año 30, 2003, en www.itamaraty.gov.br/ images/ed_biblioteca/resenhas_peb/Resenha_N92_1Sem_ 2003.pdf

, Resenha de Politica Exterior do Brasil, Brasilia, Gráfica do Ministério das Relações Exteriores, núm. 97, año 32, 2005, en www.itamaraty.gov.br/images/ed_biblioteca/resenhas_peb/ Resenha_N97_2Sem_2005.pdf

, Discursos selecionados do Presidente José Sarney, Brasilia, Fundação Alexandre de Gusmão (FUNAG), 2008, en http:/ / funag. gov.br/loja/download/510-Discurso-Selecionado-do-Presidente-Jose-Sarney.pdf

-, Discursos selecionados do Presidente Luiz Inácio Lula da Silva, Brasilia, Fundação Alexandre de Gusmão (FUNAG), 2008, en 
http://funag.gov.br/loja/download/505-discursos_selecionados_lula.pdf

, "Diplomacia cultural", 2016, en www.itamaraty.gov.br/pt$\mathrm{BR} /$ diplomacia-cultural

, "Diplomacia pública", 2017, en www.itamaraty.gov.br/pt$\mathrm{BR} /$ diplomacia-publica

Nye, Joseph S., "Limits of american power", Political Science Quarterly, vol. 117, núm. 4, 2002, pp. 545-559, en http://www-bcf. usc.edu/ stables/nye.pdf

— Soft power: The means to success in world politics, Cambridge, Public Affairs, 2004.

, "The changing nature of world power", Political Science Quarterly, vol. 105, núm. 2, 1990, pp. 177-192, en http://members.shaw.ca/compilerpress1/Anno\%20Nye.htm

oEA: Organización de los Estados Americanos y SEDI: Secretaría Ejecutiva para el Desarrollo Integral, Diálogo político, 2017.

oeA: Organización de los Estados Americanos, Quem somos, 2017.

Pinheiro, Letícia, "Traídos pelo desejo: um ensaio sobre a teoria e a prática da política externa brasileira contemporânea”, Contexto Internacional, vol. 22, núm. 2, 2000, pp. 305-335.

Poulantzas, Nicos, Poder político y clases sociales en el Estado capitalista, México, Siglo XXI, 2007.

Putnam, Robert D., "Diplomacy and domestic politics: the logic of two-level games", International Organization, Cambridge, vol. 42, núm. 3, 1988, pp. 427-460 en http://dx.doi.org/10.1017/ s0020818300027697

Ribeiro, Edgard Telles, Diplomacia cultural: seu papel na política externa brasileira, Brasilia, Fundação Alexandre de Gusmão (FUNAG), 2011, en http://funag.gov.br/loja/download/824-Diplo macia_Cultural_-_Seu_papel_na_PolItica_Externa_Brasileira_ 2011.pdf

Rubim, Antonio Albino Canelas, "Políticas culturais no Brasil: tristes tradições", Galáxia. Revista do Programa de Pós-Graduação em Comunicação e Semiótica, núm. 13, 2007, en https://revistas. pucsp.br/index.php/galaxia/article/view/1469

-, "Políticas culturais do governo Lula / Gil: desafios e enfrentamentos”, Intercom. Revista Brasileira de Ciências da Comuni- 
cação, vol. 31, núm. 1, 2008, pp. 183-203, en https:/ / repositorio. ufba.br/ri/bitstream/ri/1242/1/Antonio\%20Albino\%20Canelas\%20Rubim3.pdf

Salgado, Gabriel Melo, Layno Sampaio Pedra y Rebeca dos Santos Caldas, "As políticas de financiamento à cultura: a urgência de uma reforma”, en Antonio Albino Canelas Rubim (org.), Políticas culturais no governo Lula, Salvador, EDUFBA, 2010, pp. 87-110.

Salicnet, en www.sistemas.cultura.gov.br/comparar/salicnet/salicnet.php

Sennes, Ricardo, As mudanças da política externa brasileira nos anos 80: uma potência média recém industrializada, Porto Alegre, Editora da , 2003.

Serviço Social da Indústria (SESI) y Departamento Nacional (DN), $A$ estrutura das leis de incentivo à cultura: Parte 1, Brasilia, SESI-DN, 2007, en http://www3.sesi.org.br/Programas/src_cultura/Vol _04_P1.pdf

Silva, Rodrigo Manoel Dias da, "As políticas culturais brasileiras na contemporaneidade: mudanças institucionais e modelos de agenciamento", Sociedade e Estado, vol. 28, núm. 1, 2014, pp. 199-224, en www.scielo.br/scielo.php?script=sci_arttext\&pid=S 0102-699 22014000100011

Soulé-Kohndou, Folashadé, "L’action culturelle Sud-Sud du Brésil a travers les clubs de puissances emergentes: fonctions et usages", Cahiers des Amériques latines, vol. 80, núm. 2, 2015, pp. 31-48.

Thomson, Charles A., "The Emerging Program of Cultural Relations”, ALA Bulletin, vol. 38, núm. 2, 1943-1944, pp. 75-81.

Wallerstein, Immanuel, World-system analysis: An introduction, Londres, Duke University Press, 2004.

UNESCO: United Nations Educational, Scientific and Cultural Organization, The Organization's history, 2017, en http://www. unesco.org/new/en/unesco/about-us/who-we-are/history/

Yankelevich, Pablo, Miradas australes: propagandas, cabildeo y proyección de la Revolución Mexicana en el Río de la Plata, 1910-1930, México, Instituto Nacional de Estudios Históricos de la Revolución Mexicana, 1997. 
